\title{
Anti-inflammatory effects of inhaled carbon monoxide in patients with COPD:
} a pilot study

\author{
E. Bathoorn*, D-J. Slebos*, D.S. Postma*, G.H. Koeter*, A.J.M. van Oosterhout", \\ M. van der Toorn ${ }^{\#}$, H.M. Boezen ${ }^{\star}$ and H.A.M. Kerstjens*
}

ABSTRACT: In vitro and in vivo studies have shown that carbon monoxide (CO) has both antiinflammatory and anti-oxidant capacities. Since chronic obstructive pulmonary disease (COPD) is characterised by inflammation and oxidative stress, low-dose $\mathrm{CO}$ could be of therapeutic use. The aim of the present study was to investigate the feasibility and anti-inflammatory effects of 100125 ppm CO inhalation in patients with stable COPD.

In total, 20 ex-smoking COPD patients with post-bronchodilator forced expiratory volume in one second $\left(F E V_{1}\right)>1.20 \mathrm{~L}$ and $\mathrm{FEV}_{1} /$ forced vital capacity $<70 \%$ were enrolled in a randomised, placebo-controlled, crossover study. Effects on inflammation were measured in induced sputum and blood.

CO inhalation was feasible and patients' vital signs were unaffected; 2 h.day ${ }^{-1}$ inhalation of lowdose $\mathrm{CO}$ on 4 consecutive days led to a maximal individual carboxyhaemoglobin level of $4.5 \%$. Two exacerbations occurred in the $\mathrm{CO}$ period. $\mathrm{CO}$ inhalation led to trends in reduced sputum eosinophils (median reduction $0.25 \%$ point) and improved responsiveness to methacholine (median provocative concentration causing a $20 \%$ fall in FEV 10.85 versus $0.63 \mathrm{mg} \cdot \mathrm{mL}^{-1}$ ).

Inhalation of 100-125 ppm carbon monoxide by patients with chronic obstructive pulmonary disease in a stable phase was feasible and led to trends in reduction of sputum eosinophils and improvement of responsiveness to methacholine. Further studies need to confirm the safety and efficacy in inflammatory lung diseases.

KEYWORDS: Carbon monoxide, chronic obstructive pulmonary disease, inflammation, sputum induction

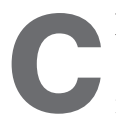

hronic obstructive pulmonary disease (COPD) is characterised by an abnormal inflammatory response to noxious gases or particles, the most important of which in the Western world is tobacco smoke [1]. However, smoking cannot explain all cases of COPD, since many nonsmokers, especially in third world countries, develop COPD without smoking. More importantly, the inflammatory response continues when smoking has been discontinued for a prolonged period of time. A long-term goal in COPD research is to elucidate the origins of the self-perpetuating inflammatory response in susceptible smokers. This knowledge is a prerequisite for novel therapeutic interventions in a disease with very few effective treatment modalities. In the present study, it is hypothesised

For editorial comments see page 1032. that endogenous haem oxygenase (HO)-1 and its downstream product, carbon monoxide $(\mathrm{CO})$, are not induced to the level necessary to protect the lung from COPD development and progression.

$\mathrm{CO}$ is generated endogenously by haem degradation. This degradation is catalysed by the enzyme HO. Of the two known enzymatically active isoforms of $\mathrm{HO}-1$ and $\mathrm{HO}-2$, only $\mathrm{HO}-1$ responds to xenobiotic induction. Constitutively expressed in many tissues, HO-2 occurs at high levels in nervous and vascular tissues and may respond to regulation by glucocorticoids [2] HO-1 is upregulated in case of tissue injury, for example during periods of tissue hypoxia and/or inflammation [3]. Both in vitro and in vivo studies suggest therapeutic options for the inhalation of $\mathrm{CO}$, since it has potent anti-inflammatory and anti-oxidant capacities [4]. In vitro, CO downregulates pro-inflammatory cytokines produced
AFFILIATIONS

*Dept of Pulmonology, Groningen Research Institute for Asthma and COPD (GRIAC),

\#Laboratory of Allergology and Pulmonary Diseases, and 'Dept of Epidemiology, University Medical Center Groningen, University of Groningen, The Netherlands.

\section{CORRESPONDENCE}

H.A.M. Kerstjens

Dept of Pulmonology

University Medical Center Groningen Postbox 30001

9700RB Groningen

The Netherlands

Fax: 3150361932

E-mail: h.a.m.kerstjens@int.umcg.nl

Received:

December 142006

Accepted after revision:

August 072007

SUPPORT STATEMENT

The present study has been registered at www.clinicaltrials.gov; ID: NCT00122694. The present study was supported by a research grant from Stichting Astma Bestrijding (the Netherlands)

STATEMENT OF INTEREST Statements of interest for $\mathrm{E}$. Bathoorn, D.S. Postma and H.A.M. Kerstjens can be found at www.erj.ersjournals.com/misc/ statements.shtml 
by macrophages [5]. In vivo studies in several animal species show that $\mathrm{CO}$ has a protective function against ischaemic injury, hyperoxic injury, graft versus host reactions, and pulmonary inflammation [6-8].

It has been postulated that a deficiency in the "HO-1-CO pathway" leads to decreased lung protection and thus may contribute to the severity of COPD. The current authors subscribe to this hypothesis, since $\mathrm{HO}-1$ expression in alveolar macrophages in smoking COPD patients is decreased compared with in smokers without COPD [9]. Additionally, the current authors have previously shown a lower HO-1 expression in ex-smokers with COPD, compared with healthy ex-smokers [10]. Also, a polymorphism linked with the development of COPD may occur in the promoter region of the HO-1 gene, resulting in a reduced inducibility of HO-1 [11]. Furthermore, it has recently been shown in vivo that adenoviral HO-1 overexpression suppresses emphysema development [12]. Therefore, a genetically dependent downregulation of HO-1 expression may arise in subpopulations, possibly linked to increased susceptibility to oxidative stress [13].

The ongoing inflammation after smoking cessation in COPD patients provides an inflammatory model for investigation of the anti-inflammatory effects of low-dose inhaled CO, bypassing the disturbing effect of variable $\mathrm{CO}$ levels inhaled during cigarette smoking. Whether the exogenous administration of $\mathrm{CO}$ reduces the inflammation and oxidative stress caused by the postulated endogenous impairment of sufficient CO generation in COPD patients is the key question of the present study. If so, inhalation of CO by COPD patients could become a realistic therapeutic option. In COPD there is much experience with the inhalation of medical gas, in the form of oxygen, both as maintenance at home and during exacerbations. It would be feasible to add a low concentration of $\mathrm{CO}$ to this oxygen.

The purpose of the present pilot study was to explore the feasibility and safety of inhalation of $\mathrm{CO}$ by stable COPD patients, as well as its anti-inflammatory potential. It was hypothesised that inhalation of $\mathrm{CO}$ reduces ongoing inflammation in patients with COPD who have stopped smoking.

\section{METHODS}

\section{Pilot}

A pilot study was first performed to assess feasibility and safety of the inhalation of $\mathrm{CO}$. $\mathrm{CO}$ was administered from a cylinder in a fixed dosage of $100 \mathrm{ppm}$ in room air
(Nederlandse Technische Gasmaatschappij, Tilburg, the Netherlands). A healthy subject inhaled this gas mixture through a non-rebreathing mask with a flow of $10 \mathrm{~L} \cdot \mathrm{min}^{-1}$ for $75 \mathrm{~min}$. Venous percentage of carboxyhaemoglobin $(\mathrm{COHb})$ was measured every $15 \mathrm{~min}$. No adverse effects occurred and the maximal $\mathrm{COHb}$ level was $2.7 \%$. Thereafter, three patients with stable COPD inhaled $95 \mathrm{ppm} \mathrm{CO}$ for $2 \mathrm{~h} \cdot$ day $^{-1}$ on 4 consecutive days. During the inhalation sessions patients were continuously observed and vital signs were monitored. Again, no adverse events occurred and the maximal venous $\mathrm{COHb}$ level reached was $3.9 \%$. It was concluded that inhalation of these low concentrations of $\mathrm{CO}$ was safe and made it possible to start with a randomised controlled clinical trial.

\section{Study design}

All patients were required to meet the following criteria: diagnosis of COPD $>1$ yr; aged 40-85 yrs; completely stopped smoking $>1$ yr previously with $\geqslant 10$ pack-yrs; post-bronchodilator forced expiratory volume in one second (FEV1)/forced vital capacity (FVC) $<70 \%$; no history of asthma; no other interfering medication or diseases; no upper/lower respiratory tract infection the previous 4 weeks. Allowed medications were short-acting anti-cholinergics and $\beta_{2}$-agonists as needed; allowed in a fixed-dose regimen were theophyllines, inhaled, nasal or systemic corticosteroids, and other nonpulmonary medication.

The study was approved by the medical ethics committee of the University Medical Center Groningen (Groningen, the Netherlands). All participants gave written informed consent.

At the inclusion visit, history was taken and physical examination performed. Spirometry was performed before and after $400 \mu \mathrm{g}$ salbutamol. Allergic status was taken from medical records and history taking. The study was randomised, placebo controlled and crossover. Patients inhaled 100-125 ppm CO for $2 \mathrm{~h}$ on 4 consecutive days. After minimally 1-week washout, room air was inhaled in the same schedule. The sequence of $\mathrm{CO}$ or placebo was randomised (fig. 1). The inhalation was blinded for the patient, physician and laboratory technician; lung function technicians were not blinded, since the $\mathrm{CO}$ measurements uncovered the blinding. Before and after the first 2-h session, cardiac frequency and blood pressure were assessed. Sputum was induced according to European Respiratory Society guidelines, but with modifications when FEV1 was <1.5 L [14, 15]. Whole sputum samples were processed for cell counts within $120 \mathrm{~min}$, as

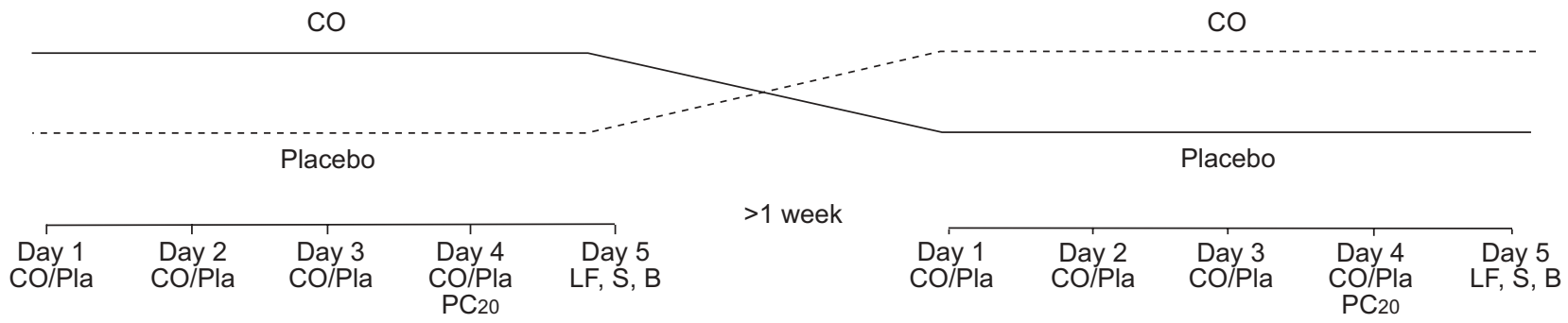

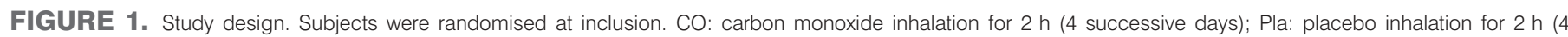

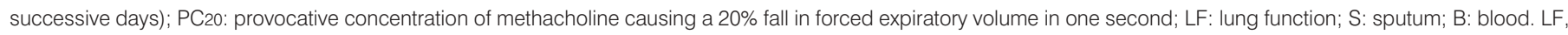
$\mathrm{S}$ and $\mathrm{B}$ were assessed $17 \mathrm{~h}$ after the last inhalation of $\mathrm{CO}$ or placebo. 
described before [16]. A total cell count was performed on sputum samples after addition of $0.1 \%$ dithiothreitol equal to the sample's volume and filtration. Viability was checked by means of trypan blue exclusion. Two slides for differential cell counts were stained with May-Grunwald-Giemsa. Differential cell counts were performed by two technicians counting 300 nonsquamous cells in a blinded fashion, and the mean was used for analysis. Percentages were calculated. Airway hyperresponsiveness was measured as the provocative concentration of methacholine causing a 20\% fall in the FEV1 (PC20) using the 2-min tidal breathing method. Health status was measured by the Clinical COPD Questionnaire [17]. After each inhalation session, patients were asked to mention any adverse symptom experienced.

Blood differential counts were analysed by flow cytometry (Coulter-STKS; Beckman Coulter, Miami, FL, USA) in the routine hospital laboratory. Serum C-reactive protein (CRP) and albumin were measured by nephelometry (Dade Behring, Leusden, the Netherlands).

Serum lipid peroxides were measured as malonaldehydethiobarbituric acid adducts by fluorimetry (Sigma-Aldrich, Zwijndrecht, the Netherlands).

Per protocol, a statistician independent of the study performed an interim analysis after the first 10 patients to determine, based on indications of therapeutic effects, whether to continue with inhalation of $100 \mathrm{ppm} \mathrm{CO}$ or increase to $125 \mathrm{ppm} \mathrm{CO}$. The trial was continued using 125 ppm CO.

\section{Statistics}

Data are expressed as median (interquartile range). Nonnormally distributed parameters were log-transformed, if this normalised the distribution. Normally distributed efficacy parameters were compared by paired t-test, non-normally distributed parameters by Wilcoxon signed rank test. The primary parameter was the difference in sputum neutrophil after $\mathrm{CO}$ and after placebo inhalation. The power calculation was performed on the primary parameter: the difference in sputum neutrophil counts after $\mathrm{CO}$ and after placebo inhalation. Limited data were available on the course of the disease as assessed by inflammatory parameters. In the present study,

\section{TABLE 1 Patient characteristics}

Subjects
Male/female
Age yrs
Smoking pack-yrs
Duration of smoking cessation yrs
FEV $1 \%$ pred
FEV 1 L
FEV $1 /$ FVC
Reversibility \% pred
Allergy yes/no
Usage of ICS yes/no

19
$18 / 1$
$67(63-70)$
$37(21-69)$
$5.7(4.6-14.6)$
$69(55-79)$
$2.2(1.8-2.5)$
$52(44-61)$
$0.1(5.1-12.6)$
$6 / 13$
$13 / 6$

Data are presented as $n$ or median (interquartile range). FEV 1 : forced expiratory volume in one second; \% pred: \% predicted; FVC: forced vital capacity; ICS: inhaled corticosteroids. the patients served as their own controls during the study, and the changes within patients were compared. A pilot study in the University Hospital Groningen with 32 COPD patients tested with a 1-week interval showed a mean change in per cent neutrophil count of $3.0 \%$ points and an SD of the difference of $11.8 \%$ points. With 20 patients in the present two-treatment crossover study, there was an $80 \%$ probability to detect a treatment difference of $\geqslant 8 \%$ with an $\alpha$ of 0.05 . Effects of treatment order and dose of $\mathrm{CO}$ were analysed post hoc using an ANOVA model, with the change in eosinophils from placebo to $\mathrm{CO}$ treatment as the dependent variable, and inhaled corticosteroids, phenotype and allergy in history as covariates.

\section{RESULTS}

\section{Patients}

Patient characteristics are shown in table 1 . Of the 20 enrolled patients, 18 completed the study. One patient withdrew consent after randomisation but before the start of the first inhalation session and was not included in analyses. One patient discontinued the study due to a serious adverse event after completing the $\mathrm{CO}$ period (see Safety and adverse events). One patient had only a 1-day inhalation programme in the second period (placebo period), because the time schedule was too intensive for him.

\section{Safety and adverse events}

The median $\mathrm{COHb}$ reached after the fourth inhalation session of 100 ppm CO was $2.6 \%$, with a highest individual value of $3.5 \%$. After 125 ppm inhalation the median $\mathrm{COHb}$ was $3.1 \%$, with the highest individual value reaching $4.5 \%$ (table 2 ).

The adverse events are shown in table 3. During/after the CO inhalation period, two exacerbations of COPD occurred. The first patient reported increased dyspnoea and cough symptoms 1 week after inhalation of $\mathrm{CO}$, but this did not require a change in medication other than an increase in the use of bronchodilators. A full-blown exacerbation requiring hospitalisation and intubation occurred 2 months later, which recovered slowly but fully. The second patient had an exacerbation on the third day of CO inhalation, and was treated successfully at home with oral corticosteroids and bronchodilators. There were no differences in other adverse events between $\mathrm{CO}$ and placebo inhalation. There were no significant differences in change of both cardiac frequency and blood pressure between $\mathrm{CO}$ and placebo inhalation (table 2).

\section{Effects on inflammatory indices}

There was no reduction by $\mathrm{CO}$ inhalation in the primary endpoint, sputum neutrophil percentage (table 4). However, the sputum eosinophil percentage did show a trend towards reduction by $\mathrm{CO}$ inhalation ( $\mathrm{p}=0.07$; table 4 ; fig 2$)$.

In blood, no significant changes in leukocyte numbers (CO: 6.8; placebo: 6.9; $\mathrm{p}=0.36)$, malonaldehyde levels (CO: $13.4 \mu \mathrm{M}$; placebo: $14.2 \mu \mathrm{M} ; \mathrm{p}=0.53$ ), CRP levels (CO: $2.5 \mathrm{mg} \cdot \mathrm{L}^{-1}$; placebo: $\left.2.5 \mathrm{mg} \cdot \mathrm{L}^{-1} ; \mathrm{p}=0.85\right)$ or erythrocyte sedimentation rates $(\mathrm{CO}$ : $6.0 \mathrm{~mm} \cdot \mathrm{h}^{-1}$; placebo: $7.0 \mathrm{~mm} \cdot \mathrm{h}^{-1} ; \mathrm{p}=0.21$ ) were found.

The first nine patients were treated with $100 \mathrm{ppm} \mathrm{CO}$, the last 10 with 125 ppm. Post hoc analysis showed that there were no differences in effects between 100 and 125 ppm CO on sputum neutrophils and eosinophils. The randomised treatment order 


\begin{tabular}{lccc}
\hline TABLE 2 & Safety parameters & & \\
& CO & Placebo & p-value \\
\hline $\begin{array}{l}\text { Median COHb \% } \\
\text { Highest COHb \% }\end{array}$ & $2.7(2.1-3.4)$ & $0.2(0.1-0.7)$ & $<0.01$ \\
$\begin{array}{l}\text { Change in cardiac frequency } \\
\text { beats } \cdot \text { min }^{-1}\end{array}$ & 4.5 & 1.7 & $<0.01$ \\
$\begin{array}{l}\text { Change in systolic blood } \\
\text { pressure } \mathbf{m m H g}\end{array}$ & $10(-11.3-4)$ & $-4(-15-0.0)$ & 0.08 \\
$\begin{array}{c}\text { Change in diastolic blood } \\
\text { pressure } \mathbf{m m H g}\end{array}$ & $6.0(-5.0-15)$ & $10(0.0-20)$ & 0.80 \\
\hline
\end{tabular}

Data are presented as median (interquartile range), unless otherwise stated. $\mathrm{CO}$ : carbon monoxide; $\mathrm{COHb}$ : carboxyhaemoglobin. Median and highest $\mathrm{COHb} \%$ are measured after the fourth inhalation of each round. Changes in vital signs are expressed as the value after subtracting the value before the first inhalation session. $1 \mathrm{mmHg}=0.133 \mathrm{kPa}$.

was also of no influence on the effects of treatment on these parameters.

\section{Effects on lung function and health status}

$\mathrm{CO}$ inhalation resulted in a trend in improvement of responsiveness to methacholine (median $\mathrm{PC} 20$ after $\mathrm{CO}$ inhalation 0.85 versus $0.63 \mathrm{mg} \cdot \mathrm{mL}^{-1}$ after placebo inhalation; $\mathrm{p}=0.098$; fig. 3). There was no effect of the $\mathrm{CO}$ inhalation on FEV1, FEV1/FVC, specific airway conductance or on the health status, as measured by the Clinical COPD Questionnaire (table 5).

\section{DISCUSSION}

The present study is the first to explore the therapeutic potential of low-dose $\mathrm{CO}$ inhalation by patients with stable COPD. The inhalation was feasible, and it resulted in trends towards therapeutic effects in reducing sputum eosinophils and improving the responsiveness to methacholine. The trends found in the present pilot study are useful for the design and power calculations of further studies of this novel pathway in the treatment of COPD.

The first objective of the pilot study was to explore the safety and feasibility of inhalation of $\mathrm{CO}$ in patients with stable
COPD. Inhalation of CO by healthy subjects has been applied previously in clinical trials that were performed to assess the clearance of $\mathrm{COHb}$ after $\mathrm{CO}$ intoxication. In the current study, the dosage of $\mathrm{CO}$ at $\mathrm{COHb}$ levels was titrated below the levels of $\mathrm{COHb}$ "achieved" with smoking of 20 cigarettes day $^{-1}$ where the $24-\mathrm{h}$ average $\mathrm{COHb}$ levels reach $5.3 \%$ on average, with peaks $>6 \%$ [19]. A protocol of $100 \mathrm{ppm} \mathrm{CO}$ for $2 \mathrm{~h}$ has been shown in a previous study in healthy young males to lead to $\mathrm{COHb}$ levels of $\sim 4 \%$ [20]. Therefore, the present study explored the therapeutic effects of $\mathrm{CO}$ at this protocol, at doses well within what was expected to be safe. Indeed, the inhalation of $100 \mathrm{ppm}$ led to a maximal $\mathrm{COHb}$ level of $3.1 \%$ in patients with COPD and the highest $\mathrm{COHb}$ level reached with 125 ppm was $4.5 \%$, which is in the range of the maximal $\mathrm{COHb}$ values the current authors had expected.

To further assess the safety, vital signs were measured before and after the first inhalation session and adverse events recorded. A significant effect of the inhaled $\mathrm{CO}$ on vital signs was not found. One patient reported haemoptysis. This patient had a long history of frequent haemoptysis of unknown origin before the present trial. There were two exacerbations in the $\mathrm{CO}$ periods; one patient experienced a COPD exacerbation starting on day 4 of $\mathrm{CO}$ inhalation, $18 \mathrm{~h}$ after the last inhalation. A severe exacerbation occurred in another patient, 2 months after the last inhalation. Both patients had experienced regular exacerbations in the past, and the current authors speculate, but can in no way prove, that these problems were not caused by the $\mathrm{CO}$ inhalation itself. The present study is underpowered to differentiate with any certainty whether these exacerbations occurred coincidentally during/after $\mathrm{CO}$ inhalation, or were caused by inhalation of $\mathrm{CO}$.

The second objective of the present pilot study was to explore the effects of inhaled CO on airway and systemic inflammation and oxidative stress. The primary end-point was sputum neutrophil counts, an end-point chosen since neutrophils are the predominant cells in sputum after smoking cessation along with eosinophils [21]. Additionally, $\mathrm{CO}$ has been shown to reduce neutrophil counts in ovalbumin-induced airway inflammation in vivo $[8,22]$. The sputum neutrophil levels did not change significantly. Nevertheless, total cell count showed a downward trend, but with a large spread. The

\section{TABLE 3 Adverse events}

co

Placebo

\section{Serious adverse events}

COPD exacerbation requiring intensive care 2 months after $\mathrm{CO}$ inhalation

\section{Adverse events}

COPD exacerbation on third day of $\mathrm{CO}$ inhalation

Headache

Dry mouth

Dizziness

Haemoptysis

Cough
1

$\begin{array}{ll}1 & 0 \\ 3 & 2 \\ 2 & 1 \\ 1 & 1 \\ 1 & 1 \\ 1 & 0\end{array}$

Data are presented as n. CO: carbon monoxide; COPD: chronic obstructive pulmonary disease 
TABLE 4 Sputum inflammatory indices

\begin{tabular}{|c|c|c|c|c|}
\hline & $\mathrm{CO}$ & Placebo & Difference $^{\#}$ & p-value \\
\hline Total $\times 10^{6}$ cells $\cdot \mathrm{mL}^{-1}$ & $3.3(1.6-6.1)$ & $5.1(2.9-10.4)$ & $-0.20(-3.54-1.38)$ & 0.55 \\
\hline Eosinophils \% & $0.75(0.30-1.55)$ & $1.0(0.65-2.58)$ & $-0.25(-1.05--0.13)$ & 0.07 \\
\hline Macrophages \% & $17.8(13.4-30.2)$ & $19.9(13.0-33.7)$ & $-2.25(-6.58-2.95)$ & 0.22 \\
\hline Lymphocytes \% & $1.6(1.1-2.4)$ & $1.6(1.0-2.8)$ & $-0.30(-1.00-0.55)$ & 0.63 \\
\hline
\end{tabular}

Data are expressed as median (interquartile range). CO: carbon monoxide. ${ }^{\#}$ : the $\mathrm{CO}$ effect, calculated as the placebo value subtracted from the corresponding CO value.

$\mathrm{p}$-value for the reduction in eosinophil percentages approached significance $(\mathrm{p}=0.07)$. The reduction in absolute eosinophil counts yielded the same p-value of 0.07 . The reduction in eosinophils could have been influenced by the use of inhaled steroids, since steroids suppress sputum eosinophils in COPD [23]. In total, 13 patients were on regular inhaled steroids. It is possible that a larger, and significant, reduction in sputum eosinophils would have occurred had these patients not been on maintenance inhaled steroids. However, post hoc analyses did not show differences in trends in effects by $\mathrm{CO}$ in inhaled steroid users and nonusers. The reduction in eosinophil numbers is not totally unexpected, since animal models showed that inhalation of $\mathrm{CO}$ or cigarette smoke containing $\mathrm{CO}$ reduces airway and lung eosinophilia [8, 22]. It is tempting to speculate that next to the many and overriding deleterious effects of cigarette smoke, certain components might also exert beneficial effects. To be clear, in the current authors' opinion these potential beneficial effects of $\mathrm{CO}$ (and perhaps of other components of cigarette smoke, such as nitric oxide and nicotine) do not sufficiently counterbalance the harmful effects.

A trend $(p=0.098)$ has been demonstrated towards improvement in responsiveness to methacholine by $\mathrm{CO}$. Both the animal models previously mentioned showed a reduction in pulmonary eosinophils and an improvement in responsiveness to methacholine $[8,22]$. The present study supports the theory that inhalation of $\mathrm{CO}$ reduces eosinophil counts and improves responsiveness to methacholine. The improvement in hyperresponsiveness could be caused by a reduction of eosinophils, although in an earlier report the correlation between responsiveness to methacholine and sputum eosinophil counts in patients with COPD did not reach significant levels $(\rho=-0.32$; $\mathrm{p}=0.085$ ) [24]. It could also be caused by a direct protective effect of $\mathrm{CO}$ on the airway smooth muscles, since CO is also a neurotransmitter causing bronchodilation in the airways via cyclic guanosine monophosphate [25].

There are two important methodological issues to discuss. The most important is that the study was not designed to detect significant changes in sputum eosinophils and responsiveness to methacholine. Post hoc power analysis showed that 31 patients would have been needed to cause the same median effect size of $0.25 \%$ point reduction in the present study to be significant with $80 \%$ power and $\alpha 0.05$. The second is that the current authors did not have a baseline measurement before the second phase of the crossover. However, no evidence of a period effect (carry-over effect) was found in the ANOVA analysis. Therefore, the washout period of $\geqslant 1$ week seems long enough.

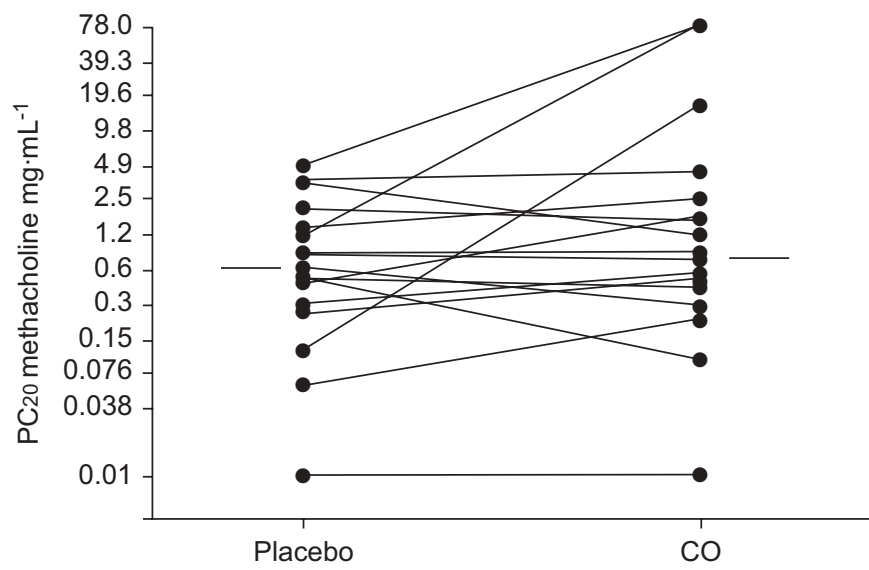

FIGURE 3. Change in provocative methacholine concentration causing a $20 \%$ fall in forced expiratory volume in one second (PC20). Data are presented as individual changes $(\bullet)$ and group medians $(-)$
FIGURE 2. Change in sputum eosinophils. Data are presented as individual changes

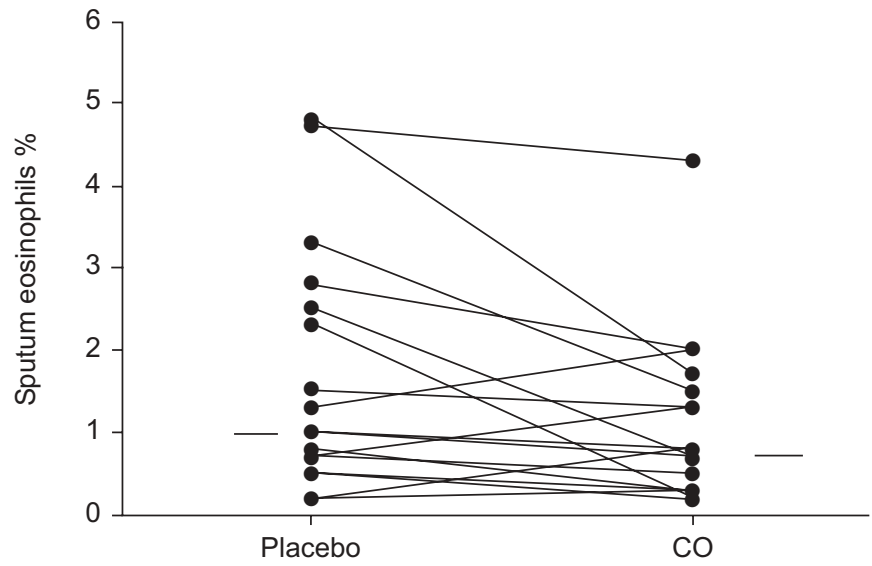

EUROPEAN RESPIRATORY JOURNAL 


\begin{tabular}{|c|c|c|c|}
\hline & $\mathrm{CO}$ & Placebo & p-value \\
\hline $\mathrm{PC}_{20}$ methacholine $\mathrm{mg} \cdot \mathrm{mL}^{-1}$ & $10.85(0.29-3.92)$ & $0.63(0.28-1.71)$ & 0.098 \\
\hline FEV 1 L & $1.8(1.5-2.3)$ & $1.8(1.5-2.4)$ & 0.94 \\
\hline FVC L & $3.8(3.5-4.4)$ & $4.0(3.4-4.4)$ & 0.44 \\
\hline FEV $_{1} /$ FVC $\%$ & $49(38-54)$ & $48(41-53)$ & 0.39 \\
\hline sGaw $1 / \mathrm{kPa} \cdot \mathrm{s}$ & $0.55(0.33-1.07)$ & $0.49(0.35-0.75)$ & 0.23 \\
\hline $\mathrm{CCQ}$ & $1.0(0.6-1.6)$ & $0.9(0.6-1.7)$ & 0.88 \\
\hline \multicolumn{4}{|c|}{$\begin{array}{l}\text { Data are presented as median (interquartile range). Lung function was } \\
\text { measured pre-bronchodilator. CO: carbon monoxide; PC20: provocative } \\
\text { concentration causing a } 20 \% \text { fall in forced expiratory volume in one second } \\
\text { (FEV1); FVC: forced vital capacity; sGaw: specific airway conductance; CCQ: } \\
\text { Clinical COPD Questionnaire (higher numbers signify a worse health status; a } \\
\text { difference of } 0.4 \text { is the minimal clinically important difference [18]). }\end{array}$} \\
\hline
\end{tabular}

The lack of overall significant changes could be due to several reasons. There was little reference for the concentration, duration and frequency of $\mathrm{CO}$ inhalation to start with. The $\mathrm{COHb}$ half-time is $\sim 340 \mathrm{~min}$ [20]. Therefore, inhaled $\mathrm{CO}$ at the concentrations used is largely cleared in $24 \mathrm{~h}$, which makes repetitive inhalation of $\mathrm{CO}$ on consecutive days noncumulative and, therefore, feasible. For safety reasons, the current authors preferred to start with a low $\mathrm{CO}$ concentration and divided the exposition over 1 week. To investigate whether these choices of dose, duration and frequency led to the expected $\mathrm{COHb}$ levels and therapeutic results in the trial, a statistician independent of the present study performed an interim analysis after the first 10 patients had completed the trial. Based on predefined criteria, the statistician determined that the study should be continued using 125 ppm CO. Post hoc analysis did not show any trends of larger effects by inhalation of the higher dose, but the groups were small. The concentration used was cautious and there is margin for inhalation of higher concentrations. Other schedule options, such as a shorter exposition with higher concentrations, a severaltimes-daily exposition, or more consecutive days could lead to different results. Intuitively, one would opt for higher cumulative doses. However, it is not a given fact that higher concentrations would have larger effects. The concentrations of CO used in the present study are already $\sim 20$-fold higher than physiological alveolar levels as measured in exhaled air, and carbonyl stress might counteract the anti-inflammatory effects [26]. Nevertheless, in an in vitro study a positive dose-response effect was observed: larger anti-inflammatory effects by higher $\mathrm{CO}$ concentrations in a dose range from 50-500 ppm [27]. The optimal scheme and concentration of $\mathrm{CO}$ inhalation needs to be elucidated in future trials.

If the hurdles of optimal dosing and timing of $\mathrm{CO}$ inhalation can be overcome, it would also be interesting to speculate about other indications than those in stable COPD, such as COPD exacerbations and severe asthma. Several studies have shown that both inflammation and oxidative stress are more increased during COPD exacerbations than in stable COPD, with concomitant upregulation of HO-1 [28-30]. Severe asthma would be another tempting indication for $\mathrm{CO}$ treatment to explore for its allergenic component, since $\mathrm{CO}$ has been proven to be antiinflammatory in models of allergen-induced inflammation [8]. In addition to the anti-inflammatory capacities, the bronchodilating capacity of $\mathrm{CO}$ makes pulmonary diseases an attractive field to explore for indications.

In conclusion, inhalation of low-dose carbon monoxide by patients with stable chronic obstructive pulmonary disease is well tolerated, feasible and safe with respect to the peak carboxyhaemoglobin levels reached and the lack of effects on haemodynamics. Whether there is some increased risk of exacerbations remains to be determined. Inhalation of 100-125 ppm carbon monoxide led to trends towards reduction in sputum eosinophils and improvement of bronchial responsiveness. This indicates that inhaled carbon monoxide might have therapeutic effects in chronic obstructive pulmonary disease. With these data, future studies should define more optimal schemes and doses, and assess the anti-inflammatory and anti-oxidative stress capacities, as well as the potential therapeutic capacity, of carbon monoxide inhalation.

\section{ACKNOWLEDGEMENTS}

The authors would like to thank I. Sloots, B. Dijkhuizen, J. Zwaagstra, J.M.Vonk, N.H.T. ten Hacken and the Lung Function Department (all University Medical Center Groningen, Groningen, the Netherlands) for all lung function measurements.

\section{REFERENCES}

1 Anthonisen NR, Connett JE, Kiley JP, et al. Effects of smoking intervention and the use of an inhaled anticholinergic bronchodilator on the rate of decline of FEV1. The Lung Health Study. JAMA 1994; 272: 1497-1505.

2 Maines MD, Trakshel GM, Kutty RK. Characterization of two constitutive forms of rat liver microsomal heme oxygenase. Only one molecular species of the enzyme is inducible. J Biol Chem 1986; 261: 411-419.

3 Otterbein LE, Choi AM. Heme oxygenase: colors of defense against cellular stress. Am J Physiol Lung Cell Mol Physiol 2000; 279: L1029-L1037.

4 Slebos DJ, Ryter SW, Choi AM. Heme oxygenase-1 and carbon monoxide in pulmonary medicine. Respir Res 2003; 4: 7.

5 Otterbein LE, Bach FH, Alam J, et al. Carbon monoxide has anti-inflammatory effects involving the mitogen-activated protein kinase pathway. Nat Med 2000; 6: 422-428.

6 Fujita T, Toda K, Karimova A, et al. Paradoxical rescue from ischemic lung injury by inhaled carbon monoxide driven by derepression of fibrinolysis. Nat Med 2001; 7: 598-604.

7 Sato K, Balla J, Otterbein L, et al. Carbon monoxide generated by heme oxygenase- 1 suppresses the rejection of mouse-to-rat cardiac transplants. J Immunol 2001; 166: 4185-4194.

8 Chapman JT, Otterbein LE, Elias JA, Choi AM. Carbon monoxide attenuates aeroallergen-induced inflammation in mice. Am J Physiol Lung Cell Mol Physiol 2001; 281: L209-L216.

9 Maestrelli P, Páska C, Saetta M, et al. Decreased haem oxygenase- 1 and increased inducible nitric oxide synthase 
in the lung of severe COPD patients. Eur Respir J 2003; 21: 971-976.

10 Slebos DJ, Kerstjens HA, Rutgers SR, Kauffman HF, Choi AM, Postma DS. Haem oxygenase-1 expression is diminished in alveolar macrophages of patients with COPD. Eur Respir J 2004; 23: 652-653.

11 Yamada N, Yamaya M, Okinaga S, et al. Microsatellite polymorphism in the heme oxygenase-1 gene promoter is associated with susceptibility to emphysema. Am J Hum Genet 2000; 66: 187-195.

12 Shinohara T, Kaneko T, Nagashima Y, Ueda A, Tagawa A, Ishigatsubo Y. Adenovirus-mediated transfer and overexpression of heme oxygenase $1 \mathrm{cDNA}$ in lungs attenuates elastase-induced pulmonary emphysema in mice. Hum Gene Ther 2005; 16: 318-327.

13 van Beurden WJ, Smeenk FW, Harff GA, Dekhuijzen PN. Markers of inflammation and oxidative stress during lower respiratory tract infections in COPD patients. Monaldi Arch Chest Dis 2003; 59: 273-280.

14 Djukanović R, Sterk PJ, Fahy JV, Hargreave FE. Standardised methodology of sputum induction and processing. Eur Respir J Suppl 2002; 37: 1s-2s.

15 Pizzichini MM, Pizzichini E, Clelland L, et al. Sputum in severe exacerbations of asthma: kinetics of inflammatory indices after prednisone treatment. Am J Respir Crit Care Med 1997; 155: 1501-1508.

16 Rutgers SR, Timens W, Kaufmann HF, van der Mark TW, Koëter GH, Postma DS. Comparison of induced sputum with bronchial wash, bronchoalveolar lavage and bronchial biopsies in COPD. Eur Respir J 2000; 15: 109-115.

17 van der Molen T, Willemse BW, Schokker S, ten Hacken NH, Postma DS, Juniper EF. Development, validity and responsiveness of the Clinical COPD Questionnaire. Health Qual Life Outcomes 2003; 1: 13.

18 Kocks JW, Tuinenga MG, Uil SM, van den Berg JW, Stahl E, van der Molen T. Health status measurement in COPD: the minimal clinically important difference of the clinical COPD questionnaire. Respir Res 2006; 7: 62.

19 Zevin S, Saunders S, Gourlay SG, Jacob P, Benowitz NL. Cardiovascular effects of carbon monoxide and cigarette smoking. J Am Coll Cardiol 2001; 38: 1633-1638.
20 Peterson JE, Stewart RD. Absorption and elimination of carbon monoxide by inactive young men. Arch Environ Health 1970; 21: 165-171.

21 Rutgers SR, Postma DS, ten Hacken NH, et al. Ongoing airway inflammation in patients with COPD who do not currently smoke. Thorax 2000; 55: 12-18.

22 Melgert BN, Postma DS, Geerlings M, et al. Short-term smoke exposure attenuates ovalbumin-induced airway inflammation in allergic mice. Am J Respir Cell Mol Biol 2004; 30: 880-885.

23 Perng DW, Wu CC, Su KC, Lee YC, Perng RP, Tao CW. Inhaled fluticasone and salmeterol suppress eosinophilic airway inflammation in chronic obstructive pulmonary disease: relations with lung function and bronchodilator reversibility. Lung 2006; 184: 217-222.

24 Willemse BW, ten Hacken NH, Rutgers B, LesmanLeegte IG, Timens W, Postma DS. Smoking cessation improves both direct and indirect airway hyperresponsiveness in COPD. Eur Respir J 2004; 24: 391-396.

25 Cardell LO, Ueki IF, Stjarne P, et al. Bronchodilatation in vivo by carbon monoxide, a cyclic GMP related messenger. Br J Pharmacol 1998; 124: 1065-1068.

26 Paredi P, Kharitonov SA, Leak D, Ward S, Cramer D, Barnes PJ. Exhaled ethane, a marker of lipid peroxidation, is elevated in chronic obstructive pulmonary disease. Am J Respir Crit Care Med 2000; 162: 369-373.

27 Morse D, Pischke SE, Zhou Z, et al. Suppression of inflammatory cytokine production by carbon monoxide involves the JNK pathway and AP-1. J Biol Chem 2003; 278: 36993-36998.

28 Papi A, Bellettato CM, Braccioni F, et al. Infections and airway inflammation in chronic obstructive pulmonary disease severe exacerbations. Am J Respir Crit Care Med 2006; 173: 1114-1121.

29 Rahman I, Skwarska E, MacNee W. Attenuation of oxidant/ antioxidant imbalance during treatment of exacerbations of chronic obstructive pulmonary disease. Thorax 1997; 52: 565-568.

30 Tsoumakidou M, Tzanakis N, Chrysofakis G, Siafakas NM. Nitrosative stress, heme oxygenase- 1 expression and airway inflammation during severe exacerbations of COPD. Chest 2005; 127: 1911-1918. 